\title{
Numerical modelling of oil spill in New York Bay
}

\author{
Ali Cemal Toz*, Burak Koseoglu, Cenk Sakar \\ Dokuz Eylul University, Turkey \\ Maritime Faculty \\ *Corresponding author's e-mail: ali.toz@deu.edu.tr
}

Keywords: New York Bay, ADIOS, GNOME, numerical modelling, oil spill.

\begin{abstract}
New York Bay is one of the most important transition regions of ships trading to east America. The region plays an important role in the commerce of the New York metropolitan area. The area is surrounded with the coasts that have various levels of environmental sensitivity. The area accommodates high diversity of native ecosystems and species that are rather vulnerable in case of oil spill. Thus getting well informed about the likelihood, or fate, of oil spills around this region is of great importance so that proactive measures can be taken. The purpose of this study is to investigate the oil spill and predict the future accidents likely to be encountered around the Bay of New York. Two trajectory models have been conducted for the study. ADIOS (Automated Data Inquiry for Oil Spills), has been conducted for natural degradation calculations, and, GNOME (General NOAA Operational Modeling Environment), has been conducted for surface spread simulation. The results gained through these efforts are hoped to be useful for many organizations dealing with oil spill response operations and contribute to an effective and efficient coordination among the relevant institutions.
\end{abstract}

\section{Introduction}

When oil is spilled into the sea it undergoes a number of physical and chemical changes; some of which lead to its removal from the sea surface, while others cause it to persist. The fate of spilled oil in the marine environment depends upon factors such as quantity spilled, the oil's initial physical and chemical characteristics, the prevailing climatic and sea conditions and whether the oil remains at sea or is washed ashore (ITOPF 2002).

Water movement quickly breaks this film up into slicks, which drift on the water surface, separated by areas of open water, and, for some of the oil, into droplets which are dispersed in the first few meters of the water column. The air, wind, light, swell and the water itself affect these slicks by a combination of physical and chemical processes that are known as evaporation, emulsification, dissolution, oxidation, and sedimentation. Aquatic organisms biologically break up the molecules of certain hydrocarbons, a process known as biodegradation. Weathering processes of oil in water are shown detailed in Fig. 1 (CEDRE 2005).

Each process is affected by environmental changes in different periods of time as shown in Fig. 1. As soon as oil is released into the environment, it undergoes significant property changes. For example, oil begins to spread as soon as it is spilled but it does not spread uniformly. Any shear in the surface current will cause stretching and even a slight wind will cause a thickening of the slick in the downwind direction (Lehr et al. 2002).

Evaporation begins as soon as the oil is released. The rate of evaporation is highest for light oils. Virtually all components of $\mathrm{C}_{12}$ and below evaporate within half a day (12 hours). For most crude oils the rate of evaporation is over $50 \%$ in the same period. Hydrocarbon liquid separate from crude oil due to changes in temperature and pressure about $98 \%$ which is known as condensation process. Since the most toxic components (e.g. benzene, toluene and xylene) are among these more volatile fractions, spilled crude quickly loses its toxicity - often within a few hours. Evaporation is also accelerated by high wind speed, turbulence, air, sea and oil temperature (DNV 2011). While evaporation reduces the volume of the surface slick, emulsification increases it. The turbulent energy in the surrounding water can cause small droplets of water to get mixed into the oil, forming a water-in-oil emulsion. The amount of water and water droplet size distribution affect the viscosity and temporal stability of the emulsion. A fully emulsified, stable emulsion may contain eighty to ninety percent water (Lehr et al. 2002). Biodegradation gradually destroys oil spills and oil seeps by the sequential metabolism of various classes of compounds present in the oil. When biodegradation occurs in an oil reservoir, the process dramatically affects the fluid properties and hence the value and producibility of an oil accumulation (Michael 1990).

\section{Mathematical model}

In this section some of available algorithms describing physical and chemical weathering processes are described. Short period processes are described individually making use of available physical and environmental data (e.g. wind speed, oil composition, etc.). 
a)

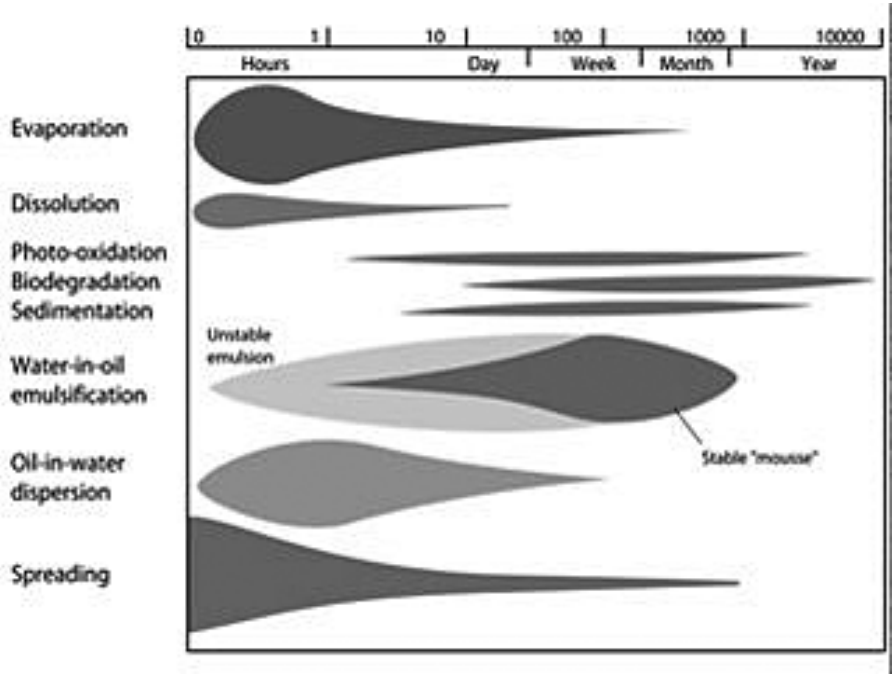

b)

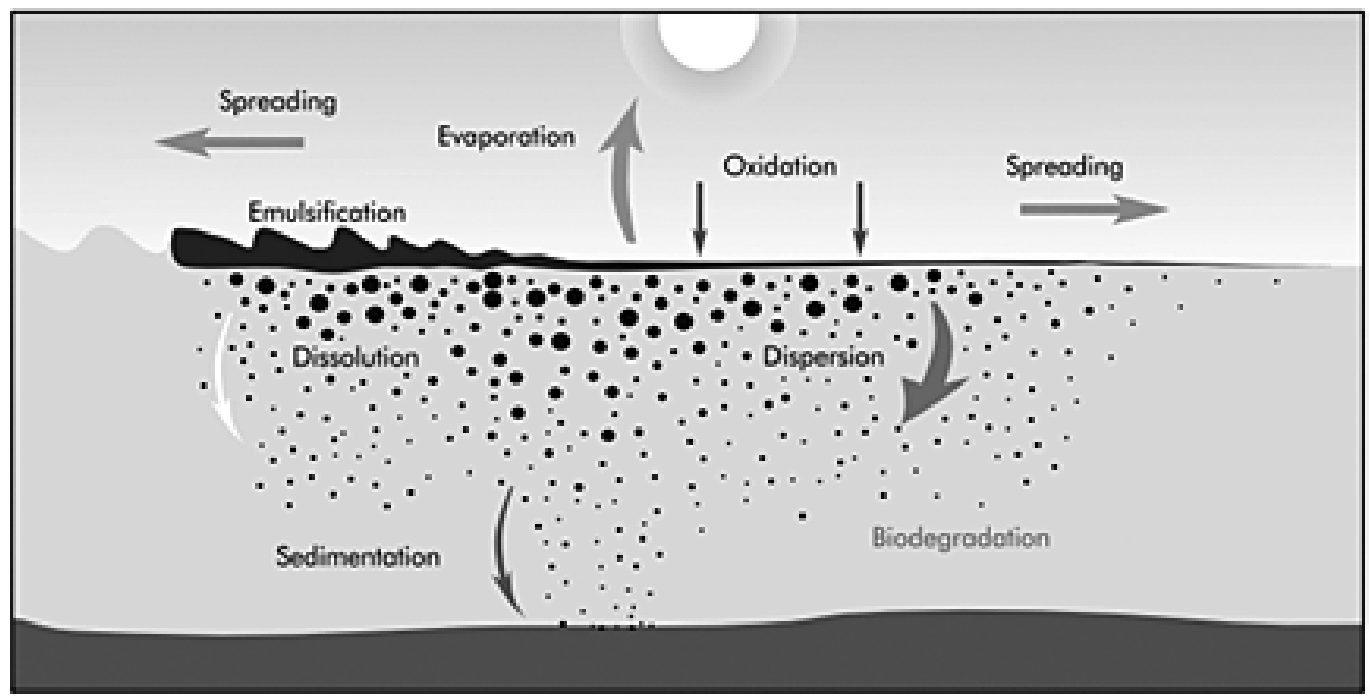

Fig. 1. Processes acting on spilled oil Source: ITOPF 2002

\section{Surface spread}

Spread of low pour point oil released on water is probably the most dominant process in the first stage of a spill. Since spreading strongly influences later processes such as evaporation and dispersion, it is logical to discuss this process first (Sebastio and Suares 1995). This process describes the spreading of oil the first few hours after the start of an oil spill (Vos 2005). Spreading is important in determining the fate of spilled oil through evaporation, emulsification, and natural dispersion. Emulsification and evaporation lead to decreased oil\&water density difference, and increased pour point; these can be used to estimate the cessation of spreading as described by the classical gravity\&viscous equations of Fay and Hoult (Reed et al. 1999).

The most widely used spreading model is the one developed by Fay (1969). In the spreading process Fay distinguishes three phases, each one being determined by the dominant spreading and retarding forces involved. The first phase is the gravityinertial spreading which lasts only a few minutes except for large spills. The third phase, tension-viscous phase, occurs when the slick may be dispersed or broken into separate slicks. So it is common that spill models consider mainly the second phase, known as the gravity-viscous spreading, for the simulation of spreading. The spill model programs divide the slick up into separate Lagrangian elements that are individually transported by wind stress, surface currents, Fay gravity-viscous forces, and random turbulence. Following the suggestion of Ahlstrom (1975), $D_{\text {Fay }}$ is given by;

$$
D_{\text {Fay }}=\Delta_{\mathrm{p}-\mathrm{w}}\left(\frac{\Delta_{w} g \cdot V^{2}}{\sqrt{v_{w}}}\right)^{1 / 3} \cdot t^{-1 / 2}
$$

Here, $\Delta_{\mathrm{p}-\mathrm{w}}$ is the relative oil water density, $\mathrm{g}$ is gravitational acceleration, $\mathrm{V}$ is initial spill volume, $\mathrm{v}_{\mathrm{w}}$ is the kinematic viscosity of water, and $t$ is the time after spill release. Added to this diffusion coefficient is a second diffusion coefficient designed to represent eddy diffusion of the surface water. Based on dye studies, Elliot and Hurford (1989) conclude that such a process is non-Fickian, and that a time dependent diffusion parameter better represents empirical results (Lehr et al. 2002). Drifting of oil due to the advection is mainly due to winds and 
currents. Assuming the placing of oil at the air water interface would not change the shear stress. Hoult (1972) suggested the wind driven current speed is approximately $3 \%$ of wind velocity. The drift due to tidal currents was simply taken to be tidal current velocity. When both wind-driven currents and tidal currents are present, he suggested simply adding the two vector quantities as shown in Fig. 2 (Soltanpour et al. 2013). If the oil slick is close to land and the wind speed is less than $10 \mathrm{~km} / \mathrm{h}$, the slick generally moves at a rate that is $100 \%$ of the surface current and approximately $3 \%$ of the wind speed. If the wind speed is more than $20 \mathrm{~km} / \mathrm{h}$, however, and the slick is on the open sea, wind predominates in determining the slick's movement (Fingas 2015).

Probably the most important cause of long term oil spreading is wind stress on the slick and surface water. Observations at past spills have resulted in a rule-of thumb that the oil slick moves at approximately three percent of the wind speed measured at ten meters above the water surface. Roughly two thirds of this movement represents stokes drift of the surface waves. The remaining one represents the movement of the slick along the water surface (Lehr et al. 2002).

\section{Evaporation}

Evaporation is usually the most important weathering process in the first days immediately following a spill. Evaporation may be responsible for the loss of one-third to two-thirds of an oil spill mass within a few hours or a day (Jordan and Payne 1980). Rapid initial loss of the more volatile fractions is followed by progressively slower loss of less volatile components. A number of parameters contribute to the rate of evaporation of oil on water (Speight and Arjoon 2012).
*** Properties of the oil: Light oil evaporates more rapidly than heavier oil.

*** Temperature: Higher temperatures increase the rate of evaporation.

*** Wind speed: Oil evaporates more rapidly with increasing wind speed.

*** Area of contact of oil with the atmosphere: The greater the area, the more rapid the evaporation.

Components of spilled oil evaporate at varying rates and are transported and diluted by atmospheric processes as shown in Table 1.

Since the rate of spreading depends on the viscosity of the oil, light oils evaporate more rapidly, due both to an increase in exposed area and their higher percentage of lighter components. Estimates of evaporative losses are required in order to assess the persistence (lifetime) of the spill, and are also the basis for estimates of changes in oil properties with time. Simple methods have been widely used, mainly based on an analytical model proposed by Stiver and Mackay (1984).

If a liquid, of vapor pressure $\mathrm{P}\left(\mathrm{P}_{\mathrm{a}}\right)$, is spilled over an area of a $\left(\mathrm{m}^{2}\right)$, the rate of evaporation is given by (Stiver and Mackay 1984);

$$
N=k_{a} P /(R T)
$$

where $\mathrm{N}$ is the molar flux $(\mathrm{mol} / \mathrm{s}), \mathrm{k}_{\mathrm{a}}$ is the mass transfer coefficient under the prevailing wind conditions $(\mathrm{m} / \mathrm{s}), \mathrm{R}$ is the gas constant $\left[8.314 \mathrm{~Pa} \cdot \mathrm{m}^{3} /(\mathrm{mol} \cdot \mathrm{K})\right]$, and $\mathrm{T}$ is the environmental temperature $(\mathrm{K})$. Equation 1 can be arranged to give (Fingas 2013);

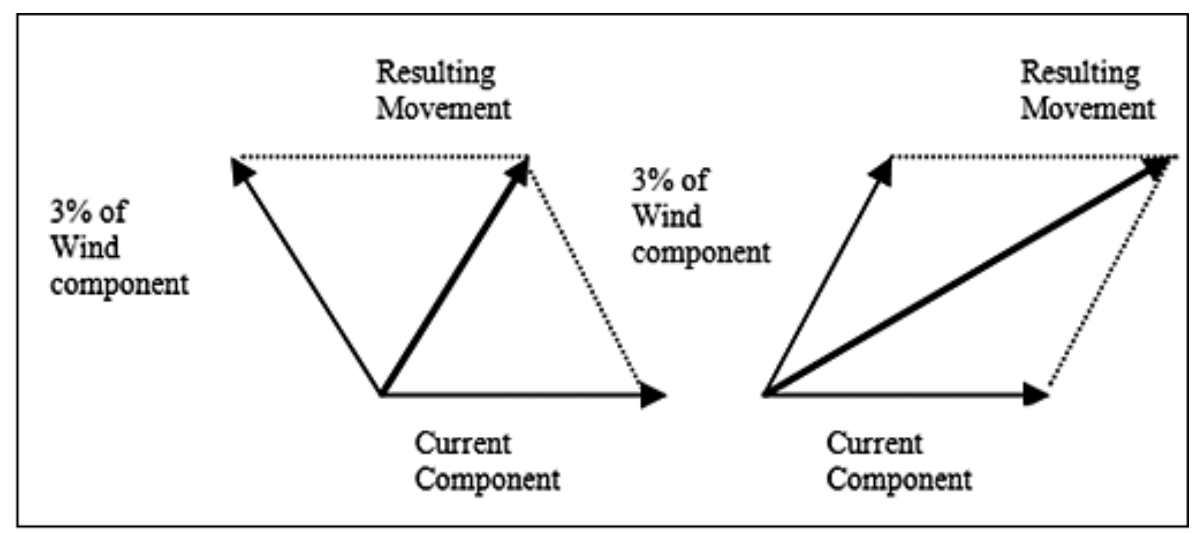

Fig. 2. The resultant oil movement's surface current and wind drift vectors* Source: Fingas 2015

*Note: The vectors are shown in 'velocity'

Table 1. Approximate evaporation for various classes of oil

\begin{tabular}{|cccc|}
\hline Oil Type & 12-Hour Evaporation* & 48-Hour Evaporation & Total Fraction Evaporated \\
\hline Group 1 (Gasoline) & $50-100 \%$ & $100 \%$ & $100 \%$ \\
\hline Group 2 (Diesel) & $10-40 \%$ & $25-80 \%$ & $100 \%$ \\
\hline Group 3 (Medium Crude) & $5-15 \%$ & $10-25 \%$ & $35 \%$ \\
\hline Group 4 (Heavy Oils) & $1-3 \%$ & $5-10 \%$ & $15 \%$ \\
\hline
\end{tabular}

$\left.{ }^{*}\right)$ Lower limits are for $5^{\circ} \mathrm{C}$ and the upper limit for $30^{\circ} \mathrm{C}$ and a moderate wind speed of $5 \mathrm{~m} / \mathrm{s}$ Source: ITOPF 1987 


$$
d F_{v} / d t=k_{a} P_{v} /\left(V_{0} R T\right)
$$

where $F_{v}$ is the volume fraction evaporated, $t$ is time (s), $v$ is the liquid's molar volume $\left(\mathrm{m}^{3} / \mathrm{mol}\right)$, and $\mathrm{V}_{\mathrm{o}}$ is the initial volume of spilled liquid $\left(\mathrm{m}^{3}\right)$. Rearranging gives (Jordan and Payne 1980);

$$
d F_{v}=\left[P_{v} /(R T)\right]\left(k_{a} d t / V_{d}\right)
$$

or

$$
d F_{v}=H \cdot d \theta
$$

The right-hand side of Eq. 4 has been separated into two dimensionless groups. The group $\mathrm{k} t / \mathrm{V}$ is termed the "evaporative exposure" and is denoted as $\theta$. The evaporative exposure is a function of time, the spill area and volume (or thickness), and the mass transfer coefficient (which is dependent on the wind speed). The evaporative exposure can be viewed as the ratio of exposed vapor volume to the initial liquid volume (Fingas 2013).

The group $\mathrm{P}_{\mathrm{v}} /(\mathrm{RT})$ or $\mathrm{H}$ is a dimensionless Henry's law constant or ratio of the equilibrium concentration of the substance in the vapor phase $[\mathrm{P} /(\mathrm{RT})]$ to that in the liquid $(1 / \mathrm{v})$. It is a function of temperature but not of other environmental conditions (Fingas 2013).

The product $\mathrm{H} \theta$ is thus the ratio of the amount which has evaporated (oil concentration in vapor times vapor volume) to the amount originally present. If the liquid is pure, $\mathrm{H}$ is independent of $\mathrm{F}_{\mathrm{v}}$, and Eq. 5 can be integrated directly to give (Stiver and Mackay, 1984);

$$
F_{v}=H \theta
$$

If $\mathrm{k}_{\mathrm{a}}$ and temperature are constant, the evaporation rate is constant and evaporation is complete ( $F_{v}$, is unity) when $\theta$ achieves a value of $1 / \mathrm{H}$. If the liquid is a mixture, $\mathrm{H}$ depends on $\mathrm{F}_{\mathrm{v}}$ and Eq. 5 can only be integrated if $\mathrm{H}$ is expressed as a function of $\mathrm{F}_{\mathrm{v}}$; i.e., the principal variable of vapor pressure is expressed as a function of composition. The evaporation rate slows as evaporation proceeds in such cases. If the liquid is pure, the resistance to mass transfer must lie entirely in the air phase because there is no necessity for the substance to diffuse in the liquid phase to the interface. The mass transfer coefficient $\mathrm{k}$ is then entirely an air-phase resistance term. If the liquid is a mixture, it is possible that there is a contributing liquid-phase resistance, especially if the substance has a high air-liquid partition coefficient (i.e., a high vapor pressure) or if the liquid is viscous. We assume here that the air-phase resistance dominates. The other approach is to use a gas stripping technique with an exit gas rate $\mathrm{G}\left(\mathrm{m}^{3} / \mathrm{s}\right)$. If the exit gas is saturated, the evaporation rate will be $\mathrm{GP} /(\mathrm{RT})$ (molls) and (Fingas 2015);

$$
d F_{v} / d t=[G P /(R T)]\left(v / V_{d}\right)
$$

or

$$
d F_{v}=H d \theta
$$

The evaporative exposure $\theta$ is now defined as $\mathrm{Gt} / \mathrm{V}_{\mathrm{o}}$ and is the actual ratio of vapor volume to liquid volume. The identical nature of Eq.4 and Eq.7 suggests that if surface (tray) and stripping experimental data are plotted as $F_{v}$ vs. $\theta$, the points should lie on a common line, $\theta$ being defined either as $\mathrm{k}_{\mathrm{a}} \mathrm{t} / \mathrm{V}_{\mathrm{o}}$ or Gt $/ \mathrm{V}_{0}$ (Stiver and Mackay 1984).

\section{Natural dispersion}

Natural dispersion is the dispersion of oil, under the influence of waves, into finely divided droplets below the slick. This increases the total surface area of the oil, and so speeds biodegradation (Blaikley et. al. 1977). It is expected that the dispersion rate is a function of the slick thickness, the oil-water interfacial tension, the oil density and viscosity, the sea state and, particularly, the fraction of sea covered by breaking waves (Papadimitrakis et al. 2011).

In nearly all of the above references and in various simulation models of oil slick behavior at sea, use is made of an empirical expression proposed by Delvinge and Sweeney (1988) for the rate of oil mass dispersion in the water column, per unit surface area, caused by the breaking of surface waves. That relationship is, mainly, characterized by its dependence on the oil type, the energy of breaking waves lost into turbulence, and the fraction of sea surface covered by whitecaps, per unit time; the latter (two) quantities are estimated empirically (Paradimitrakis et al. 2011).

$$
F_{W C}=C_{b}\left(U_{w}-U_{w i}\right) / T_{w}
$$

Where the local wind speed $\mathrm{U}_{\mathrm{w}}$ is measured at the height of $10 \mathrm{~m}$ above MWL, $\mathrm{U}_{\mathrm{wi}}$ represents a wind speed necessary for the "initiation" of breaking $\left(\approx 5 \mathrm{~ms}^{-1}\right), \mathrm{T}_{\mathrm{w}}$ is a characteristic wave period, and $\mathrm{C}_{\mathrm{b}}\left(\approx 0.032 \mathrm{~s} \mathrm{~m}^{-1}\right)$ is a constant; A semi-imperical relation for the energy dissipation per unit surface area in a breaking event given by:

$$
D_{b a} \approx 0.0034 p_{w} g H_{r m s}^{2}
$$

Where $\mathrm{H}_{\mathrm{rms}}$ represents root mean square (rms) value of the wave height in the wave field ( $m), p_{w}$ is water density in $\left(\mathrm{kg} / \mathrm{m}^{3}\right)$ and $\mathrm{g}$ represents acceleration as a result of gravity $\left(\mathrm{m} / \mathrm{s}^{2}\right)$ (Delvigne 1993).

The close interdependence of oil spill weathering processes is well known. Many of the advances in our understanding of weathering over the past decade are rejected in an increased awareness of these interactions.

\section{Materials and method}

The purpose of this study is to provide immediate trajectory and fate predictions in the event of a real spill incident, and thereby help priorities oil spill response activities in New York Bay. This study also aims to perform risk assessments for important resources (beaches, fisheries, marine wildlife, marine parks and other protected coastal areas) in affected region, and to help develop coastal planning and management.

In this study two softwares have been used to simulate weathering process of oil. For the analysis of sea circulation General NOAA Operational Modeling Environment (GNOME) model, which predicts the fate of past and current oil spills, has been operated for surface spread simulation. Automated 
Data Inquiry for Oil Spills (ADIOS) model has been conducted for natural dispersion and evaporation calculations. ADIOS integrates a library of approximately one thousand oils with a short-term oil fate and cleanup model to help estimate the amount of time that spilled oil will remain in the marine environment, and to develop cleanup strategies (NOAA 2012). ADIOS calculations combine real-time environmental data, such as wind speed, with chemical and physical property information in its oil library. The program provides output on oil weathering parameters such as evaporation, dispersion into the water column, and changes in oil density and viscosity. Aside from the oil characteristics, winds and currents are the main factors that have effects on the spill trajectory (Lighthill 1978).

\section{Study site and experimental design}

The New York Bay was selected for model area in this study. The area is surrounded with the coasts that have different levels of environmental sensitivity. From ocean beaches to a maritime forest, freshwater ponds, and salt water marshes, the area contains many environments with a large variety of wildlife. For example Raritan Bay is the habitat for over 90 species of fishes. The shorelines of Raritan Bay host migratory shorebirds and Neotropical migrant landbirds. The area accommodates high diversity of native ecosystems and species that are rather vulnerable in case of oil spill. Environmental sensitivity map of study area and spill point are shown in Fig 3 and Fig 4.

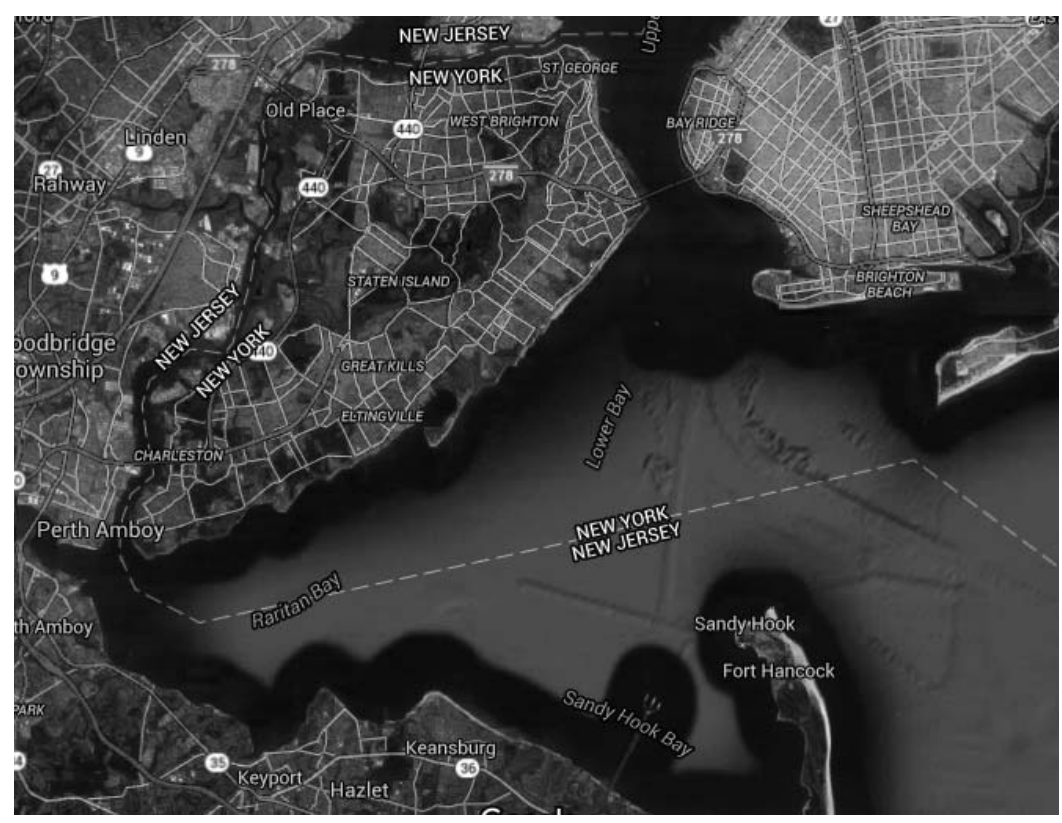

Fig. 3. Study Area Map: New York Bay, USA Source: Google Maps 2014

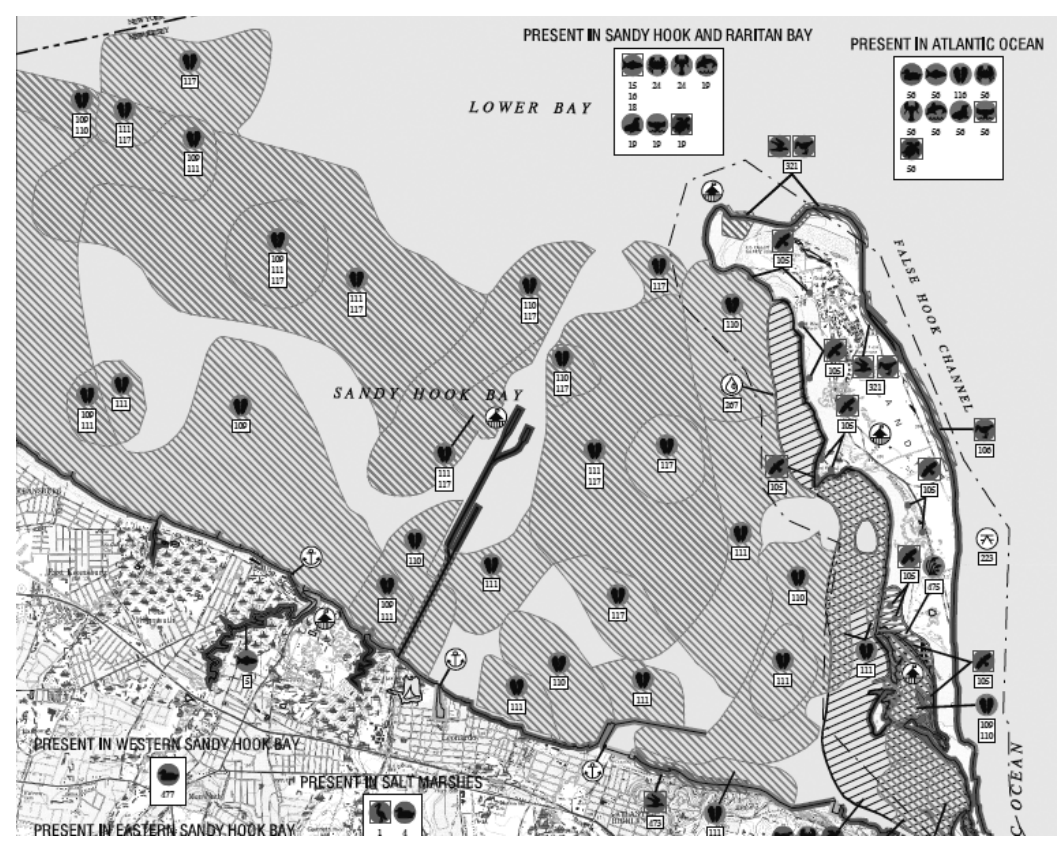

Fig. 4. Environmental Sensitivity Map: Sandy Hook / New York Bay, USA Source: NOAA 2001 
Heavy industry accelerates development to satisfy the needs of population for the region, and many industries have increased their capacities. This development has affected marine transportation in the region. The ship traffic in New York Bay has been increasing day by day. Thus, the risk of marine pollution is increasing. The one considerable accident resulted in marine pollution have been noticed in New York Bay. In 1995 the single-hulled ship almost completed a voyage from St. Croix in the Virgin Islands to the Port Reading Terminal, about 20 miles northwest of Sandy Hook, when she struck a sand ledge two miles east of the region tearing a hole in the hull and spilling at least 300 barrels of light oil into water.

\section{Pollutants}

Two different types of pollutants have been selected for the study. The pollutants have different weathering characteristics while spilled on water, so the risks have a great variety of different physical and chemical properties. The specific material data of pollutants are shown in Table 2.

It is clear that specific properties of pollutants are quite different as shown in the table. The main weathering process determinants are quite different and have strong relationship with each other. For instance, the specific gravity which is the main determinant for spreading, and floating process has a strong relationship with viscosity. Also evaporation and dispersion processes are interlinked with boiling point, viscosity and vapor pressure. This relation is specified in terms of an initial liquid phase boiling point temperature and the gradient of this boiling point temperature versus the fraction evaporated (Reed et al. 1999). Evaporation and emulsification increase the density and viscosity of the slick. Even when freshly spilled, most oils and oil products are more viscous than water (Lehr et al. 2002).

\section{Environmental data}

The regional environmental data is obtained from long term observation statistics which was prepared by local meteorological institution. Two main environmental determinants (wind and sea current) have been considered for the study. The speed and direction of regional wind are identified in accordance with wind frequencies of which $\mathrm{W}$ direction for the year $\mathrm{S}$ direction for month of September have the highest frequency values as shown in Fig. 5.

Table 2. Physical and chemical properties of pollutants

\begin{tabular}{|lll|}
\hline & Gasoline & Fuel Oil No:6 \\
\hline Specific Gravity & $0.66-0.75\left(\right.$ Water=1) $\left(60^{\circ} \mathrm{F}\right)$ & $>0.9$ to $1.2 \mathrm{~g} / \mathrm{mL}$ \\
\hline Boiling Point & $26.7-226.7^{\circ} \mathrm{C}$ & $154-372^{\circ} \mathrm{C}$ \\
\hline Viscosity at $40^{\circ} \mathrm{C}$ & 0.64 to $0.88 \mathrm{~mm}^{2} / \mathrm{s}$ & $>300 \mathrm{cST}$ \\
\hline Vapor Pressure & $345-1,034 \mathrm{hPa}$ at $37,8^{\circ} \mathrm{C}$ & $210 \mathrm{~Pa}$ at $25^{\circ} \mathrm{C}$ \\
\hline
\end{tabular}

Source: IARC 1989

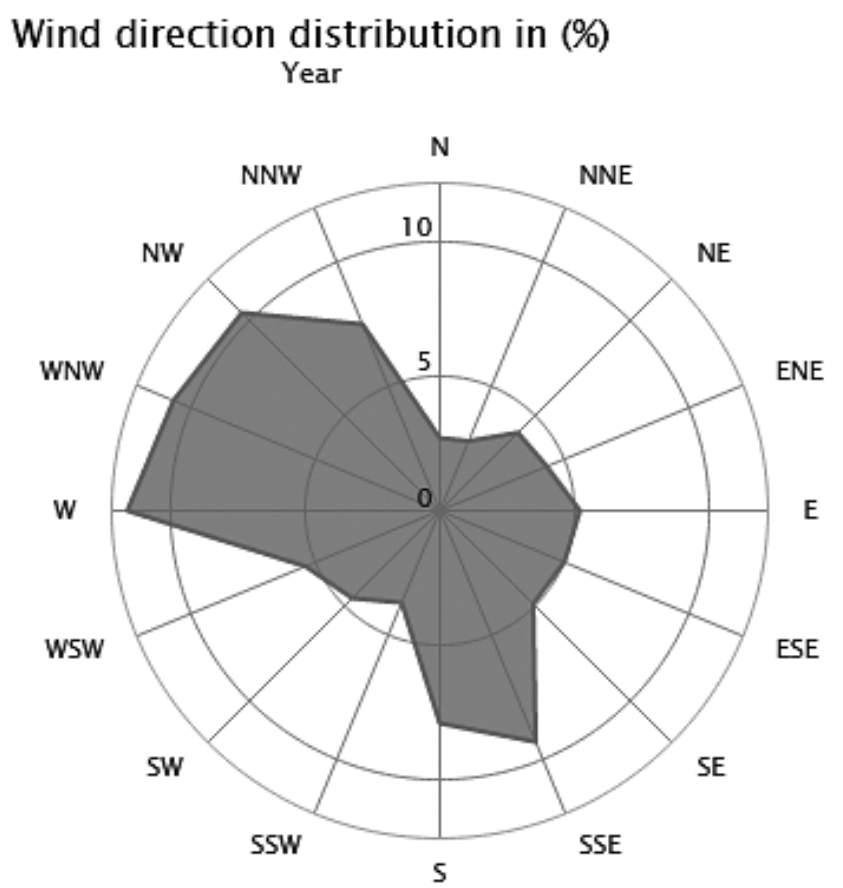

Fig. 5. Wind direction distribution in (\%), (1995-2007) Source: WF 2014 
GNOME has a location file for New York harbor which contains information about local oceanographic condition. The wind characteristics at study area between the years of 1995 and 2007 were considered for the model. Two different wind characteristics $(\mathrm{S} / 8 \mathrm{kts}-\mathrm{W} / 9 \mathrm{kts})$ have been considered in the model. The wind data was put into the model manually and then software started simulation with the combination of other related components.

\section{Scenarios and model}

Four different scenarios have been identified and conducted in the model as shown in Table 3. Gasoline and Fuel Oil have been selected as pollutant in this study due to different weathering characteristics. The scenarios run with hourly period with particular environmental data and spill amount. Every spill scenario starts at the geographical point of Long: $74^{\circ} 00^{\prime} \mathrm{W} / \mathrm{Lat}: 40^{\circ} 30^{\prime} \mathrm{N}$. The model has a run which is based on the actual hourly weather data. Every scenario is divided into two sub scenarios regarding the spill amount and run period. The first and the third scenarios run for gasoline spill and the second and the fourth scenarios run for fuel oil spill. As for running scenarios, meteorological data and amount of spill have been put into the model by user in order to simulate the weathering process. The summary of studied scenarios with spill information and meteorological data set are shown in Table 3.

The GNOME and the ADIOS software have been used to run scenarios to simulate fate and trajectory of oil spilled from the tanker located near the Sandy Hook. Main oil characteristics and related information already installed in the software have been selected by the user. The GNOME has been operated for surface spread simulation and the ADIOS has been conducted for natural dispersion and evaporation process.

\section{Results and discussion}

The printouts of each scenario show that the movement of spill was mostly affected by tidal current and surface wind forces. Tracking route of oil spill present that area affected from spill is changing for both scenarios. Most of the Gasoline evaporates during the first hours due to low viscosity. As fuel oil is more viscose, the floating part is greater than evaporation and dispersed.

Coney Island is under the risk of contamination in case of fuel oil spill with westerly wind (S:2a) within 8 hour periods.
However, for a longer period of time spill moves back to the entrance of Raritan Bay (S:2b) due to southerly tidal current forces. The scenarios with gasoline spill show that Raritan Bay is under the risk of contamination due to surface spread motion. The short period scenario (S:1a) indicates that most of oil is evaporated and dispersed naturally. However, longer period model $(\mathrm{S}: 1 \mathrm{~b})$ shows that the coasts of the model area is riskless due to quick natural degradation process.

The study shows that spill amount has also strong relationship with degradation process. The third and the fourth scenarios show that greater amount of pollutants are more resistant to degradation process compared to smaller spills. The spills with greater amount show that entrance of New York Bay is under the risk of contamination for short period model (S:3a/S:4a). The longer period model shows that Coney Island, South Beach and Breezy Point are under the risk of contamination in case of greater amount of spill.

Weathering process for each pollutant is quite different concerning different physical and chemical properties. This process is directly affected by environmental conditions. Oil degradation starts instantly when spilt on water. The figures show time dependent weathering process of each pollutant with different amount.

The figures show that only $82 \%$ of gasoline (Fig.7a) and $1 \%$ of fuel oil (Fig. $7 \mathrm{~b}$ ) is evaporated after 1 hour period. Gasoline needs approximately 3 hours to evaporate completely and disappear but fuel oil survives for longer period of time. After 6 hours' period, only $1 \%$ of fuel oil is naturally dispersed and $4 \%$ of fuel oil is evaporated. Finally, after 6 hours' period gasoline is completely degraded but $95 \%$ of fuel oil is remained on water.

The figures show that only $76 \%$ of gasoline (Fig.7c) and $1 \%$ of fuel oil (Fig. $7 \mathrm{~d}$ ) is evaporated after 1 hour period. After 2 hours' period gasoline is completely degraded but $99 \%$ of fuel oil is remained on water. After 6 hours' period only $1 \%$ of fuel oil is naturally dispersed and $3 \%$ of fuel oil is evaporated. Finally, after 6 hours' period gasoline is completely degraded but $96 \%$ of fuel oil is remained on water.

\section{Conclusion}

In this study it is clearly identified that environmental factors (wind, current, air temperature, etc.) and pollutant characteristics (viscosity, boiling point, specific gravity, etc.) are the main determinants of weathering process. The results

Table 3. Summary of studied scenarios

\begin{tabular}{|c|c|c|c|c|c|}
\hline Scenario & Oil Type & Amount $\left(\mathrm{m}^{3}\right)$ & \multicolumn{2}{|c|}{ Wind Data } & Model Run Period \\
\hline $1 \mathrm{a}$ & \multirow{2}{*}{ GASOLINE } & \multirow{2}{*}{50} & \multirow{2}{*}{ W } & \multirow{2}{*}{$9 \mathrm{kts}$} & 8 hour \\
\hline $1 b$ & & & & & 24 hour \\
\hline $2 a$ & \multirow{2}{*}{ FUEL OIL } & \multirow{2}{*}{50} & \multirow{2}{*}{ W } & \multirow{2}{*}{$9 \mathrm{kts}$} & 8 hour \\
\hline $2 b$ & & & & & 24 hour \\
\hline $3 a$ & \multirow{2}{*}{ GASOLINE } & \multirow{2}{*}{100} & \multirow{2}{*}{ S } & \multirow{2}{*}{$8 \mathrm{kts}$} & 8 hour \\
\hline $3 b$ & & & & & 24 hour \\
\hline $4 a$ & \multirow{2}{*}{ FUEL OIL } & \multirow{2}{*}{100} & \multirow{2}{*}{ S } & \multirow{2}{*}{$8 \mathrm{kts}$} & 8 hour \\
\hline $4 b$ & & & & & 24 hour \\
\hline
\end{tabular}




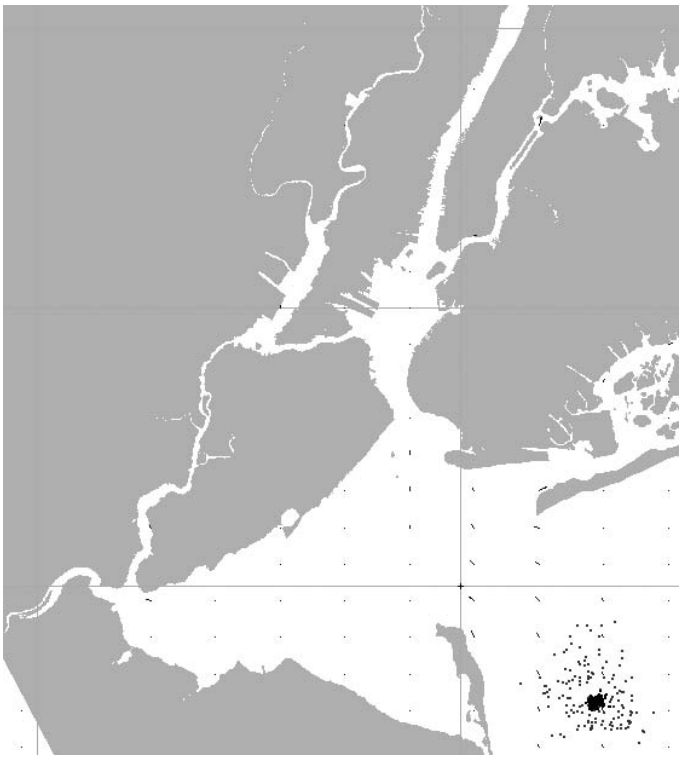

Fig. 6a. Scenario 1a (Gasoline/8 hrs)

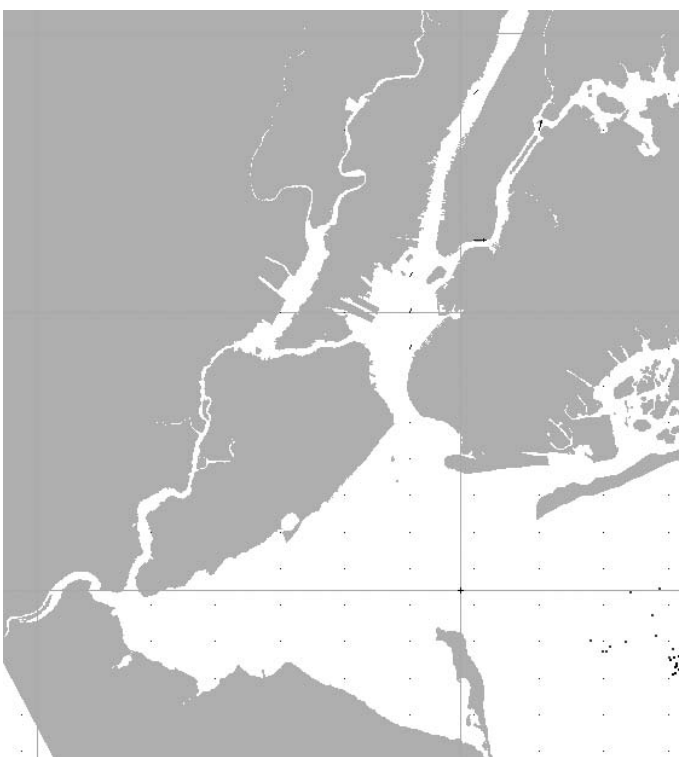

Fig. 6c. Scenario 1b (Gasoline/24 hrs)

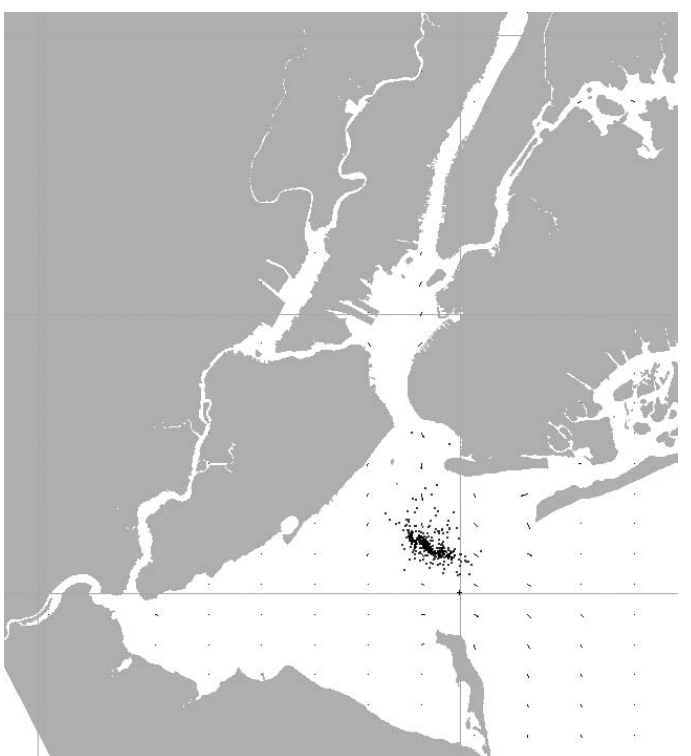

Fig. 6e. Scenario 3a (Gasoline/8 hrs)

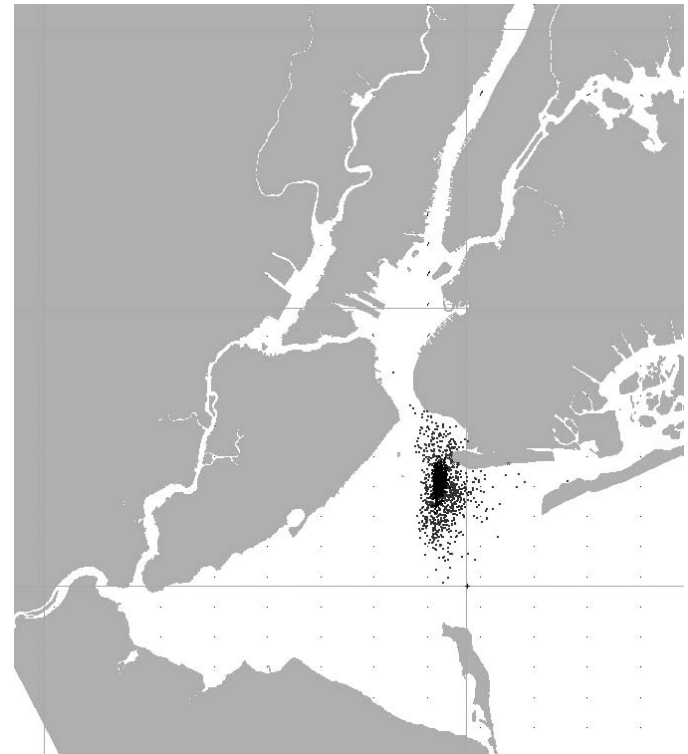

Fig. 6b. Scenario 2a (Fuel Oil/8 hrs)

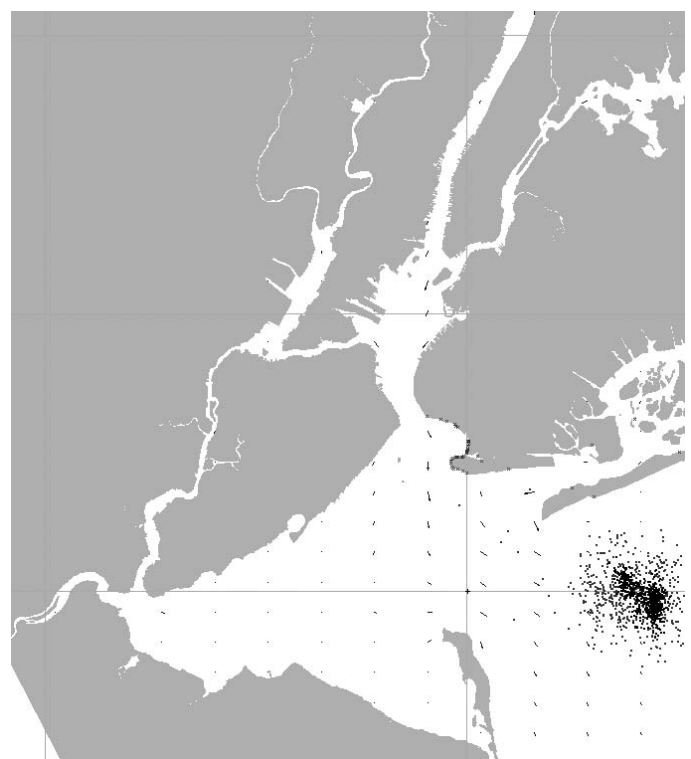

Fig. 6d. Scenario 2b (Fuel Oil/24hrs)

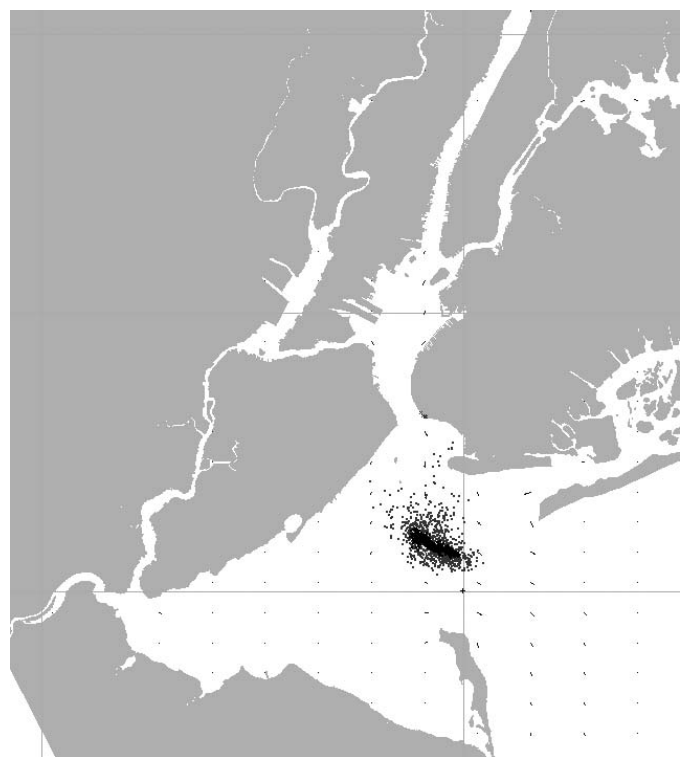

Fig. 6f. Scenario 4a (Fuel Oil/8 hrs) 


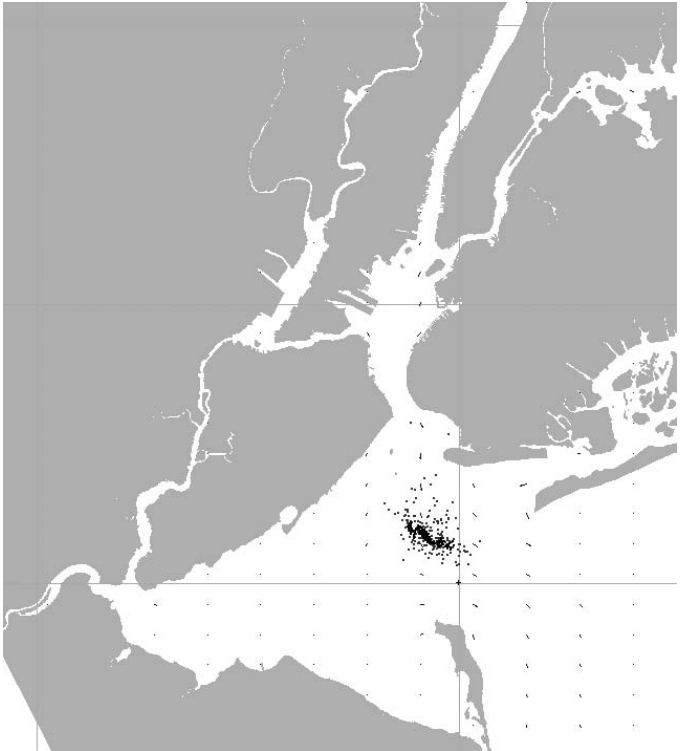

Fig. 6g. Scenario3b (Gasoline/24 hrs)

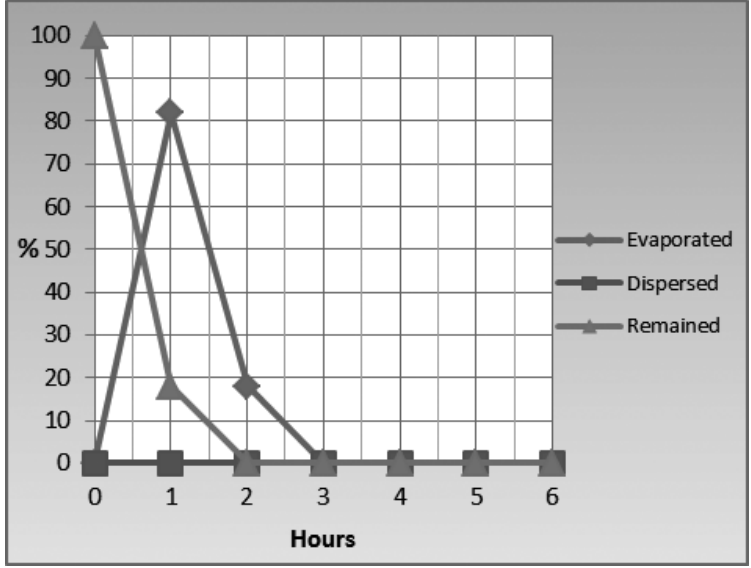

Fig. 7a. (S:1). Gasoline degradation chart

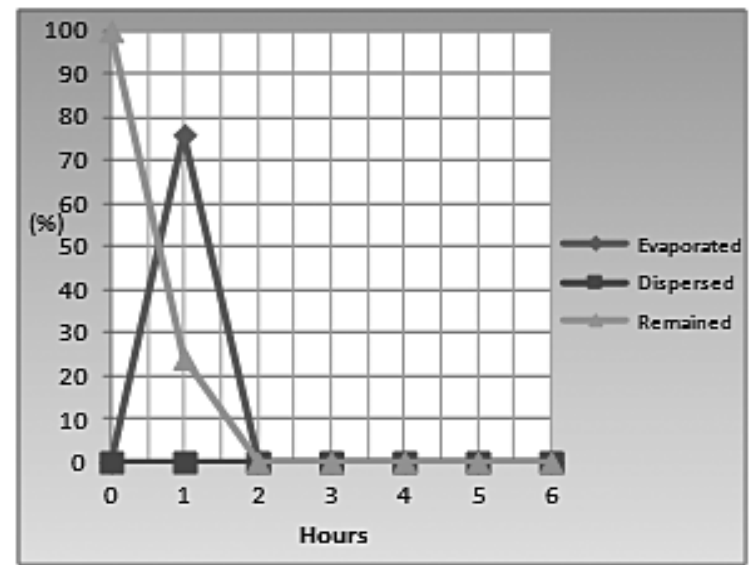

Fig. 7c. (S:3). Gasoline degradation chart

reveal that in case of gasoline spill, with average environmental conditions, there is no risk of contamination for model area due to rapid evaporation process. The study also reveals that in case of fuel oil spill there is big risk of contamination for Coney Island, Breezy Point and South Beach. In case of big spillage with $\mathrm{S}$ directed wind, the spill reaches a larger area,

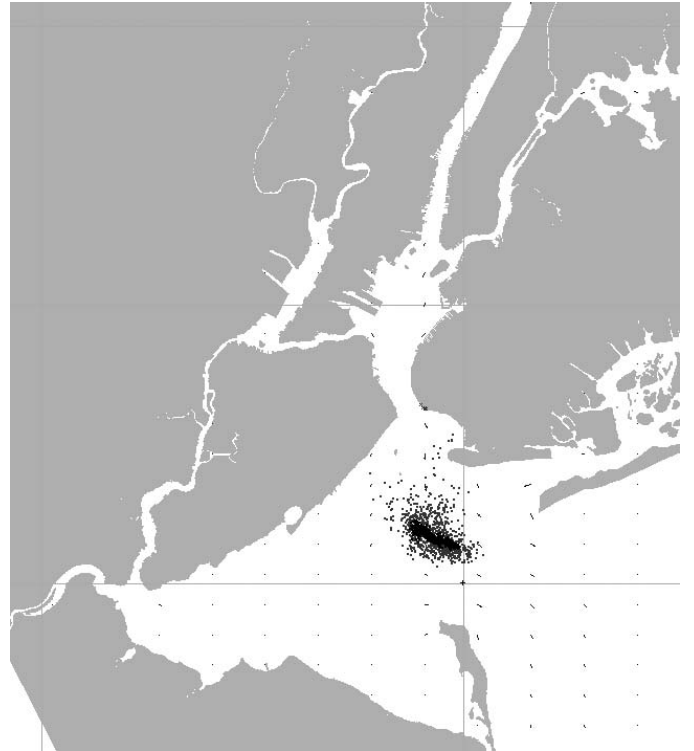

Fig. 6h. Scenario4b (Fuel Oil/24 hrs)

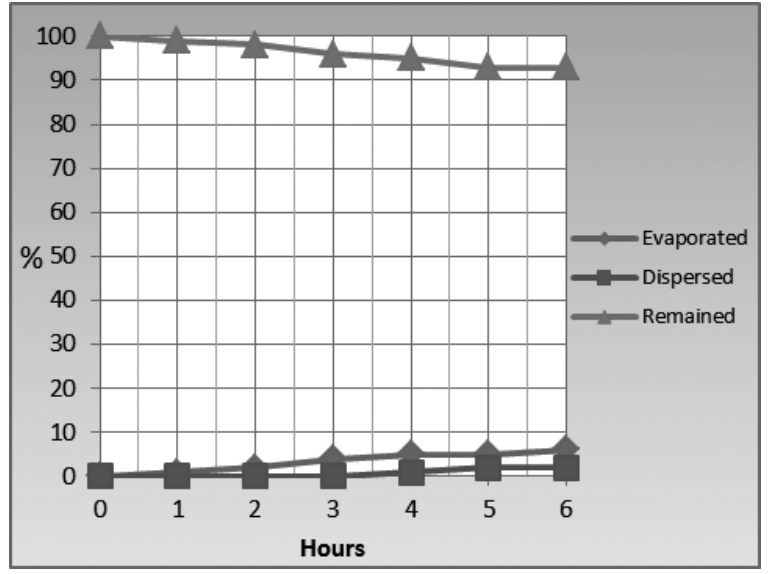

Fig. 7b. (S:2). Fuel Oil degradation chart

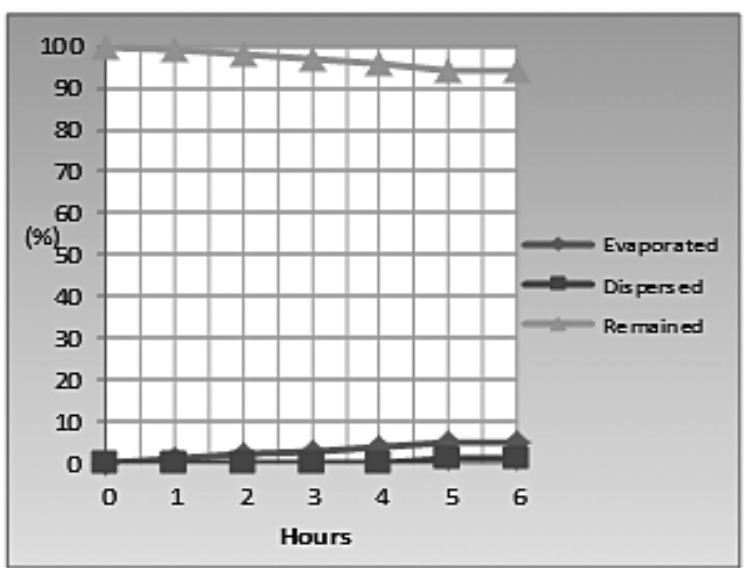

Fig. 7d. (S:4). Fuel Oil degradation chart

and the results reveal that local current conditions are much more effective than the wind conditions.

Beaching amount of fuel oil is higher than beaching amount of gasoline so the negative impact on environment is different. Not only the quantity beached but also type of oil is the main factor of contamination density. Contamination 
density determines response strategy and cleaning operations. In this study it is identified that the degradation life time is dependent on the oil type and viscosity.

This study investigated oil spill fate, which is released around New York Bay and predicted the fate of future accidents. The results will be useful for many organizations related to oil spill response operations. The information can be used to improve the emergency management systems in order to protect the human health, coastal management, and marine environment.

\section{Acknowledgements}

The authors would like to thank Dokuz Eylul University Maritime Faculty and Maine Maritime Academy of USA for financial support, providing data and supporting this project.

\section{References}

Ahlstrom, S.W. (1975). A mathematical model for predicting the transport of oil slicks in marine waters, Battelle Pacific Northwest Laboratories Richland, Wash, USA 1975.

Blaikley, D.R.G.F.L., Dietzel, A., Glass, W. \& van Kleef, P.J. (1977). SLIKTRAK - a computer simulation of offshore oil spills, cleanup, effects and associated costs, EPA/API Oil Spill Conference Proceedings, New Orleans, 1977.

Bloem, M.A., Putten, M.A, Deveci, A. \& Tuna, O. (2013). Maritime Turkey: Market Research, Maritime By Holland, Netherland, 2013.

CEDRE (2005). Black Tide, Learning Guide (http://black-tides. $\mathrm{com} / \mathrm{uk} /$ tools/learning-guide-understanding-black-tide.pdf (12.12.2014)).

Delvigne, G.A.L. (1993). Natural dispersion of oil by different sources of turbulence, International Oil Spill Conference Proceedings, pp. 415-419.

DNV (Det Norske Veritas) (2011). Report for Australian Maritime Safety Authority. Model of Oil Dispersion. DNV Project No: PP002916. Page VI.i (https://www.amsa.gov.au/formsand-publications/environment/publications/Other-Reports/ documents/DNVApp6.pdf. (10.12.2014)).

Elliot, A.J. \& Hurford, N. (1989). The influence of wind and wave shear on the spreading of a plume at sea, Oil and Chemical Pollution, 5, 347-363. doi:10.1016/S0269-8579(89)80025-5.

Fay, J.A. (1969). The spread of oil slicks on a Calm Sea, Fluid Mechanics Laboratory, Dept. of Mech. Eng. , MIT, Cambridge, Mass. doi: 10.1007/978-1-4684-9019-0_5.

Fingas, M. (2011). Evaporation modeling, Oil Spill Science and Technology, (1), pp. 201-242.

Fingas, M. (2013). Modeling oil and petroleum evaporation, Journal of Petroleum Science Research, 2(3).

Fingas, M.F. (2011). Oil spill science and technology - prevention, response, and cleanup. Gulf professional publishing (Elsevier), Burlington, MA, USA, 2011.

Hoult, D.P. (1972). Oil spreading on the sea, Annual Review of Fluid Mechanics, 4, pp. 341-368.
IARC (International Agency for Research on Cancer). (1989). http:// monographs.iarc.fr/ENG/Monographs/vol45/mono45-11.pdf. (10.12.2014)

IMO (International Maritime Organization), (2000). Catalogue of computer programs and internet information related to responding to oil spills, MEPC/Circ.367, London, 2000.

ITOPF (International Tanker Owners Federation), (2002). Fate of oil spills. The International Tanker Owner Pollution Federation Limited, London (http://www.itopf.com/marine-spills/fate/ weathering-process/ documents/tip2.pdf. (12.12.2014)).

ITOPF (International Tanker Owners Federation), (1987). Response to marine oil spills. International Tanker Owners Pollution Federation, London, published by Witherby \& Co., London, 1987.

Jordan, R.E. \& Payne, J.R. (1980). Fate and weathering of petroleum spills in the marine environment, Ann Arbor Science: Ann Arbor, MI, 1980.

Lehr, W., Jones, R., Evans, M., Simecek-Beatty, D. \& Overstreet,R. (2002). Revisions of the ADIOS oil spill model, Environmental Modelling \& Software, 17, 2, pp. 189-197.

Lighthill, M.J. (1975). Waves in fluids, Cambridge, UK: Cambridge University Press, 1975.

Michael, G. E. (1990). Effect of biodegradation on crude oils. Bulletin United States Geological Survey, 1912,59-62. MTMAC (Ministry of Transport Maritime Affairs and Communications). (2014). Deniz Ticareti 2013 İstatistikleri, Deniz Taşıtları, Denizyolu Taşımave Teşvik İstatistikleri (http://www.ubak.gov.tr/BLSM WIYS/DTGM/tr/Kitaplar/20140613_162122_64032_1_64480. $\operatorname{pdf}(10.12 .2014))$.

NOAA (2012). Automated Data Inquiry for Oil Spills, (http:// response.restoration.noaa.gov/oil-and-chemical-spills/oil-spills/ response-tools/adios.htm (07.09.2016)).

Papadimitrakis, I., Psaltaki, M. \& Markatos, N. (2011). 3-D oil spill modelling. Natural dispersion and the spreading of oil-water emulsions in the water column, Global nest. The international journal, 13, 4, pp. 325-338.

Reed, M., Johansen, Ø., Brandvik, P. J., Daling, P., Lewis, A., Fiocco, R., Mackay, R. \& Prentki, R. (1999). Oil spill modeling towards the close of the 20th century: overview of the state of the art, Spill Science \& Technology Bulletin, 5,1, pp. 3-16.

Sebastiao, P. \& Soares, G.C. (1995). Modeling the fate of oil spills at sea, Spill Science \& Technology Bulletin, 2, 2, pp. 121-131.

Soltanpour, M., Wijayaratna, N. \& Hajisalimi, Z. (2013). Numerical modeling of oil slick spread in The Persian Gulf, International Journal of Maritime Technology, 1, 1, pp. 57-66.

Speight, J.G. \& Arjoon, K.K. (2012). Bioremediation of petroleum and petroleum products, John Wiley \& Sons, 2012

Stiver, W. \& Mackay, D. 1984. Evaporation rate of spills of hydrocarbons and petroleum mixtures, Environment Science and Technology, 18, pp. 834-840.

TSMS (Turkish State Meteorological Service), (2014). (http://www. mgm.gov.tr/veridegerlendirme/il-ve-ilceler-istatistik.aspx?k=B (10.12.2014)).

Vos, R.J. (2005). Comparison of 5 oil weathering models, Werkdocument RIKZ/ZD/2005.011W Rijkswaterstaat Dienst Noordzee, Ministerie van Verkeer en Waterstaat. 